\title{
A sequential extraction method for evaluating rock-hosted elements at conditions relevant to $\mathrm{CO}_{2}$ geo- sequestration
}

G.K.W. DAWSON ${ }^{1 *}$, J.K. PEARCE ${ }^{1,2}$, D.KIRSTE ${ }^{3}$, S.D. GOLDING $^{1}$

${ }^{1}$ School of Earth and Environmental Sciences, The University of Queensland, Brisbane, QLD, 4072, Australia

(*correspondence: g.dawson@uq.edu.au)

${ }^{2}$ Center for Natural Gas, The University of Queensland, Brisbane, QLD, 4072, Australia

${ }^{3}$ Department of Earth Sciences, Simon Fraser University, Burnaby, BC V5A 1S6, Canada

Relationships between elements in rock samples, as well as how readily they can be mobilised under neutral to moderately acidic $\mathrm{pH}$ conditions, were investigated at ambient temperature and pressure. There were three extraction steps in this procedure: 1) Water soluble, weakly adsorbed, and exchangeable fractions (pure water with 0.01 mol/1 ammonium acetate at near-neutral $\mathrm{pH}$ ); 2) Strongly adsorbed elements and those incorporated in minerals and amorphous compounds that dissolve at $\mathrm{pH} 5(1 \mathrm{~mol} / \mathrm{l}$ acetic acid buffered with ammonium acetate); 3) Elements incorporated in minerals or amorphous compounds that are soluble at $\mathrm{pH} 3(1 \mathrm{~mol} / \mathrm{l}$ acetic acid buffered with ammonium acetate). The amounts of each element extracted from powdered rock samples in each step were compared to wholerock element concentrations to determine the percent element extracted. The method was tested using samples of the Precipice Sandstone from the proposed Surat Basin Carbon Capture and Storage Project in Queensland, Australia. The majority of extracted trace elements were interpreted to be hosted within carbonates and some sulfide minerals. High proportions of some of the trace elements present in the rocks were mobilised. Selected samples were investigated using Parr ${ }^{\mathrm{TM}}$ batch reactors in the presence of $\mathrm{CO}_{2}$ and artificial formation water at $12 \mathrm{MPa}$ and $60{ }^{\circ} \mathrm{C}$. Compared with the sequential extraction procedure, similar suites of elements were mobilised. The sequential extraction procedure enabled determination of how particular elements were hosted within rock samples, and helped to establish under what conditions these may be mobilised. This information feeds into both reaction path and reactive transport models of $\mathrm{CO}_{2}$ geosequestration within the proposed Precipice Sandstone reservoir formation. 